Article

\title{
Assessment of Vitamin B12 in Patients with Coronary Tortuosity
}

\author{
Vitamin B12 and Coronary Tortuosity \\ Levent Cerit 1,*, Hatice Kemal 1, Aziz Gunsel 1, Murat Uncu ${ }^{2}$, Zeynep Cerit ${ }^{3}$, Kamil Gulsen ${ }^{1}$ \\ and Hamza Duygu 1 \\ ${ }^{1}$ Department of Cardiology, Near East University Hospital, 99138 Nicosia, Cyprus; kemal.hatice@hotmail.com \\ (H.K.), draziz@hotmail.com (A.G.), drkamilgulsen@yahoo.com (K.G.), hamzakard@yahoo.com (H.D.) \\ 2 Department of Biochemistry, Near East University Hospital, 99138 Nicosia, Cyprus; drmurat@hotmail.com \\ ${ }^{3}$ Department of Pediatrics, Near East University Hospital, 99138 Nicosia, Cyprus; drceritzeyno@gmail.com \\ * Correspondence: drcerit@hotmail.com; Tel: 00903926751000-00905338761981; Fax: 00903926751000
}

\begin{abstract}
Background: Vitamin B 12 deficiency has been implicated in endothelial dysfunction and cardiovascular disease via hyperhomocysteinemia. Coronary tortuosity (CorT) is a common coronary angiography finding. The etiology, clinical implication and long term prognosis are still not well clarified. This study was conducted with the aim to evaluate the relationship between CorT and vitamin B12. Subjects and Method: The medical records of consecutive patients, who underwent coronary angiography, were retrospectively reviewed. The study group consisted of 1624 patients. Taking into consideration the inclusion criteria, 212 patients with CorT and 210 patients with normal coronary angiographies (control group) were included in the study. Vitamin B12, other biochemical parameters, clinical and echocardiographic parameters, and CorT score were evaluated in all patients. CorT is defined as fixed 3 bends during both systole and diastole, with each bend $\geq 45^{\circ}$. Results: Patients with CorT had higher prevalence of older, female gender, hypertension, current smoking. Vitamin B12 was significantly decreased in patient with CorT $(134.7 \pm 47.8$ vs $239.6 \pm 53.8 \mathrm{p}<0.001)$. On multivariate analysis age, female gender, hypertension, diabetes mellitus and vitamin B12 were independent predictors for CorT (OR 1.56; 95\% CI: 1.2471.962; p < 0.001, OR 1.628; 95\% CI: 1.376-2.048; p<0.001, OR 1.865; 95\% CI: 1.387-2.695; $<<0.001$, OR 1.362; 95\% CI: 1.184-1.726; p<0.001, OR 1.862; 95\% CI: 1.486-2.674; p<0.001, respectively). Conclusion: In our study, we have founded a significant relationship between vitamin B12 deficiency and CorT.
\end{abstract}

Keywords: vitamin B12; coronary tortuosity; coronary angiography

\section{INTRODUCTION}

Vitamin B12 is required in the metabolism of homocysteine (Hcy), which occurs through remethylation to methionine or trans-sulfuration to cysteine. Methylation of Hcy, catalyzed by methionine synthetase produces methionine [1]. Hcy-mediated increased lipid peroxidation and generation of free radicals results in inflammation and acute endothelial dysfunction, which accelerates atherosclerotic process predisposing to cardiovascular disease. Coronary artery disease is associated with higher levels of Hcy [2]. Which plays a permissive role in endothelial damage. Low vitamin B12 concentration and hyperhomocysteinemia are common in general [3].

Many studies have been undertaken to examine the relation between plasma Hcy and coronary heart disease $[4,5]$. The general outcome supports the hypothesis that an elevated plasma Hcy concentration leads to an increased risk of cardiovascular disease.

Coronary tortuosity (CorT) is a common coronary angiography finding. CorT is defined as a fixed 3 bends during both systole and diastole, in at least a single epicardial artery, with each bend 45 
change in the vessel direction [6]. The etiology, clinical implication and long term prognosis are still not well clarified. Clinical studies have demonstrated that CorT might be related to aging, hypertension, atherosclerosis and diabetes mellitus [7,8]. The CorT is associated with reversible myocardial perfusion defects and chronic stable angina [9,10]. Zegers et al. [11] demonstrated three cases of patients with the CorT and hypothesized that the CotT may lead to ischemia.

The relationship between vitamin B12 and CorT has not been studied. In the light of these knowledge, we assessed the relationship between the CorT and vitamin B12.

\section{METHODS}

The study group consisted of 1624 consecutive patients, who underwent coronary angiography due to positive treadmil test. A retrospective evaluation of consecutive patients undergoing coronary angiography was performed. Stable angina was defined as discomfort in the chest, back, jaw, shoulder or arms, typically elicited by exertion or emotional stress, and relieved by rest or nitroglycerin. All patients enrolled in the study underwent coronary angiography as a result of chest pain and objective signs of ischaemia during treadmill exercises. Taking into consideration the inclusion criteria, 212 patients with CorT and 210 patients with normal coronary angiographies (control group) were included in the study. We excluded patients with each degree of coronary lesion, previous myocardial infarction.

The data of patients were retrospectively analyzed for the demographic features, echocardiographic parameters, biochemical parameters, vitamin B12 level and CorT.

Vitamin B12 was measured by Ion Capture Microparticle enzyme immunoassay with commercial kits supplied by Abbott Laboratory. Intra assay and inter assay precision was $<\% 10$ for above parameters. B12 deficiency was defined as $<200 \mathrm{pg} / \mathrm{ml}$. The study was approved by the local ethics committee.

The patient's data including age, gender, history of hypertension (HT), diabetes mellitus $(\mathrm{DM})$, and echocardiographic variables such as ejection fraction, biochemical and hematologic parameters were received medical records.

\section{Echocardiographic Examination}

All patients underwent transthoracic echocardiography using Vivid S5 (GE healthcare) echocardiography device and Mass S5 probe (2-4 MHz). Standard two-dimensional and color flow Doppler views were acquired according to the guidelines of American Society of Echocardiography and European Society of Echocardiography [12,13]. The ejection fraction was measured according to the Simpson's method.

\section{Coronary Angiography}

All patients underwent elective coronary angiography according to the Judkins technique. Angiograms were reviewed by at least 2 nonblinded reviewing cardiologists. The left anterior descending coronary artery (LAD), the left circumflex coronary artery (LCX) and the right coronary artery (RCA) were observed by various angulations. CorT was evaluated on special angulations, LAD was assessed in right anterior oblique with cranial angulations and LCX in left anterior oblique with caudal angulations, while RCA in right anterior oblique. CotT was identified by $\geq 3$ bends (defined as $\geq 45^{\circ}$ change in vessel direction) along main trunk of at least one artery, present both in systole and in diastole (6).

Patients with DM were identified on admission as those with documented DM using either oral hypoglycemic agents or insulin treatment. Hypercholesterolemia was defined as total cholesterol at least $200 \mathrm{mg} / \mathrm{dL}$ or using antihyperlipidemic therapy on admission. Hypertension was defined as blood pressure above 140/90 mmhg or using antihypertensive therapy on admission. 


\section{Statistical Analysis}

Statistical analysis was performed using the SPSS (version 20.0, SPSS Inc., Chicago, Illinois) software package. Continuous variables were expressed as mean \pm standard deviation (mean \pm SD) and categorical variables were expressed as percentage (\%). The Kolmogorov-Smirnov test was used to evaluate the distribution of variables. Student's t-test was used to evaluate continuous variables showing normal distribution, and Mann-Whitney U-test was used to evaluate variables that did not show normal distribution. A $\mathrm{p}$ value $<0.05$ was considered statistically significant. To identify predictors of CorT, the following variables were initially assessed in a univariate model: age, hypertension, female gender, diabetes, hyperlipidemia, vitamin B12 deficiency. Significant variables in univariate analysis were then entered into a multivariate logistic-regression analysis using backward stepwise selection.

\section{RESULTS}

Prevalance of CorT was found 13\% in this study group. Coronary tortuosity and normal coronary group were composed of 212 and 210 patients respectively. The demographic characteristics of both group are summarized in Table 1.

There was no significant difference between both groups regarding hyperlipidemia and body mass index ( $41.5 \%$ vs. $40 \% \mathrm{p}=0.476,26.8 \pm 4.3$ vs. $24.6 \pm 5.1 \mathrm{p}=0.549$; respectively)(Table1)

However, there was a significant difference between both groups regarding hypertension with more hypertensive patients among the CorT group (66.5\% vs. $41.9 \%$, $\mathrm{p}<0.001)$ (Table1). There were also significant diffrence between both groups regarding age, female gender, diabetes mellitus (68.4 \pm 12.6 vs. $56.8 \pm 8.9$ p $<0.001,71.6 \%$ vs. $40 \%$ p $<0.001,45.8 \%$ vs. $20 \%$ p $<0.001$; respectively) (Table1).

Table 1. General characteristics of patients

\begin{tabular}{|c|c|c|c|}
\hline \multirow{2}{*}{ Patient Characteristics } & \multicolumn{2}{|c|}{ Coronary Tortuosity } & \multirow{2}{*}{ p } \\
\cline { 2 - 3 } & $\begin{array}{c}+ \\
(212)\end{array}$ & $\begin{array}{c}- \\
(210)\end{array}$ & \\
\hline Age (years) & $\begin{array}{c}68.4 \pm 12.6 \\
(75)\end{array}$ & $\begin{array}{c}56.7 \pm 8.9 \\
(62)\end{array}$ & $<0.001$ \\
\hline Female gender, $\mathrm{n}(\%)$ & $152(71.6)$ & $84(40)$ & $<\mathbf{0 . 0 0 1}$ \\
\hline Hypertension, $\mathrm{n}(\%)$ & $141(66.5)$ & $88(41.9)$ & $<0.001$ \\
\hline Diabetes Mellitus, $\mathrm{n}(\%)$ & $97(45.8)$ & $42(20)$ & $<0.001$ \\
\hline Current smoking, $\mathrm{n}(\%)$ & $132(62.2)$ & $66(31.4)$ & $<0.001$ \\
\hline Hyperlipidemia, $\mathrm{n}(\%)$ & $88(41.5)$ & $84(40)$ & 0.476 \\
\hline Body mass index $\left(\mathrm{kg} / \mathrm{m}^{2}\right)$ & $26.8 \pm 4.3$ & 24.65 .1 & 0.549 \\
\hline Statin therapy, $\mathrm{n}(\%)$ & $84(39.6)$ & $79(37.6)$ & 0.354 \\
\hline
\end{tabular}


There was no significant difference between both groups regarding urea, creatinine, low density lipoprotein, high density lipoprotein, total cholesterol, triglyceride, üric acid, and folic acid ( $24.4 \pm 7.3$ vs. $26.7 \pm 6.2 \mathrm{p}=0.827,0.89 \pm 0.11$ vs. $0.87 \pm 0.14 \mathrm{p}=0.839,104 \pm 19$ vs. $101 \pm 24 \mathrm{p}=0.864,41 \pm 12$ vs. $43 \pm 13 p=0.738,162 \pm 24$ vs. $157 \pm 27 \mathrm{p}=0.386,133 \pm 18$ vs. $128 \pm 19 \mathrm{p}=0.842,5.4 \pm 2.1$ vs. $5.6 \pm 1.9 \mathrm{p}=0.751$, $9.8 \pm 3.3$ vs. $10.5 \pm 3.9 \mathrm{p}=0.763$; respectively).

The median serum vitamin B12 level of the CorT group were significantly lower than that of the control group $(134.7 \pm 47.8$ vs. $239.6 \pm 53.8, \mathrm{p}<0.001)$ (Table2).

Table 2. Laboratory, and Echocardiographic Parameters

\begin{tabular}{|c|c|c|c|}
\hline \multirow{2}{*}{$\begin{array}{c}\text { Laboratory and Echocardiographic } \\
\text { Variables }\end{array}$} & \multicolumn{2}{|c|}{ Coronary Tortuosity } & \multirow[b]{2}{*}{$\mathbf{p}$} \\
\hline & $\begin{array}{c}+ \\
(212) \\
\end{array}$ & $\begin{array}{c}- \\
(210)\end{array}$ & \\
\hline White Blood Cell $\left(10^{3} / \mu \mathrm{L}\right)$ & $6.72 \pm 1.81(7.42)$ & $6.93 \pm 1.92(7.51)$ & 0.582 \\
\hline Haemoglobin (g/dl) & $13.1 \pm 2.3(14.2)$ & $13.8 \pm 1.9(14.4)$ & 0.895 \\
\hline C Reactive Protein (mg/dl) & $0,41 \pm 0,16(0.47)$ & $0.38 \pm 0,13(0.45)$ & 0.627 \\
\hline Total Cholesterol (mg/dl) & $162 \pm 24(173)$ & $157 \pm 27(169)$ & 0.386 \\
\hline High Density Lipoprotein (mg/dl) & $41 \pm 12(46)$ & $43 \pm 13(48)$ & 0.738 \\
\hline Low Density Lipoprotein (mg/dl) & $104 \pm 19(118)$ & $101 \pm 24(116)$ & 0.864 \\
\hline Triglyceride $(\mathrm{mg} / \mathrm{dl})$ & $133 \pm 18(141)$ & $128 \pm 19(138)$ & 0.842 \\
\hline Urea $(\mathrm{mg} / \mathrm{dl})$ & $28.4 \pm 7.3(30.4)$ & $26.7 \pm 6.2(29.2)$ & 0.827 \\
\hline Creatinine $(\mathrm{mg} / \mathrm{dl})$ & $0.89 \pm 0.11(0.92)$ & $0.87 \pm 0.14(0.95)$ & 0.839 \\
\hline Uric acid (mg/dl) & $5.4 \pm 2.1(6.1)$ & $5.6 \pm 1.9(6.3)$ & 0,751 \\
\hline Ejection Fraction (\%) & $62.4 \pm 5.2(64.3)$ & $63 \pm 6.1(65.6)$ & 0.783 \\
\hline Vitamin B12 (pg/ml) & $134.7 \pm 47.8(142)$ & $239.6 \pm 53.8(267)$ & $<0.001$ \\
\hline Folic acid (ng/ml) & $9.8 \pm 3.3(11.8)$ & $10.5 \pm 3.9(12.4)$ & 0.763 \\
\hline
\end{tabular}

The results of univariate analyses are presented in Table 3. On univariate analysis, age, HT, DM, female gender, hprelipidemia, creatinine, smoking, and vitamin B12 were associated with CorT (Table3). On multivariate analysis age, female gender, hypertension, diabetes mellitus and vitamin B12 were independent predictors for CorT (OR 1.56; 95\% CI: 1.247-1.962; p < 0.001, OR 1.628; 95\% CI: 1.376-2.048; p<0.001, OR 1.865; 95\% CI: 1.387-2.695; p<0.001, OR 1.362; 95\% CI: $1.184-$ 1.726; $\mathrm{p}<0.001$, OR 1.862; 95\% CI: 1.486-2.674; $\mathrm{p}<0.001$, respectively)(Table4).

Table 3. Univariate Analysis of Predictors for Coronary Tortuosity

\begin{tabular}{|c|c|c|}
\hline Predictor Variables & OR (95\% C.I.) & p \\
\hline Age (years) & $2.138(1.534-3.082)$ & $<\mathbf{0 . 0 0 1}$ \\
\hline Diabetes mellitus, $\mathrm{n}(\%)$ & $1.857(1.357-2.495)$ & $<\mathbf{0 . 0 0 1}$ \\
\hline Hypertension, $\mathrm{n}(\%)$ & $2,285(1.937-2.982)$ & $<\mathbf{0 . 0 0 1}$ \\
\hline Female gender, $\mathrm{n}(\%)$ & $2.254(1.962-3.428)$ & $<\mathbf{0 . 0 0 1}$ \\
\hline Hyperlipidemia, $\mathrm{n}(\%)$ & $1.256(1.054-1.425)$ & $\mathbf{0 . 0 0 1}$ \\
\hline Creatinine $(\mathrm{mg} / \mathrm{dl})$ & $1.332(1.037-1.568)$ & $\mathbf{0 . 0 0 1}$ \\
\hline Current smoking, $\mathrm{n}(\%)$ & $1.426(1.258-1.692)$ & $\mathbf{0 . 0 0 1}$ \\
\hline Vitamin B12 $(\mathrm{pg} / \mathrm{ml})$ & $1.851(1.375-2.247)$ & $<\mathbf{0 . 0 0 1}$ \\
\hline
\end{tabular}


Table 4. Multivariate Analysis of Predictors for Coronary Tortuosity

\begin{tabular}{|l|l|r|}
\hline Predictor Variables & OR $\mathbf{~ ( 9 5 \% ~}$ & $\mathbf{p}$ \\
\hline Age (years) & $1.56(1.247-1.962)$ & $<0.001$ \\
\hline Female gender, $\mathrm{n}(\%)$ & $1.628(1.376-2.048)$ & $<\mathbf{0 . 0 0 1}$ \\
\hline Hypertension, $(\mathrm{n} \%)$ & $1.865(1.387-2.695)$ & $<\mathbf{0 . 0 0 1}$ \\
\hline Diabetes mellitus, $(\mathrm{n} \%)$ & $1.362(1.184-1.726)$ & $<\mathbf{0 0 0 1}$ \\
\hline Vitamin B12 $(\mathrm{pg} / \mathrm{ml})$ & $1.862(1.486-2.674)$ & $<\mathbf{0 . 0 0 1}$ \\
\hline
\end{tabular}

\section{DISCUSSION}

The present study revealed that age, HT, DM, female gender, and vitamin B12 deficiency were associated with CorT. Our results are consisted with previous studies [14-16]. Li et al. [14] found that coronary tortuosity was positively correlated with hypertension. They assumed that the arteries may become tortuous due to reduced axial strain and hypertensive pressure in an elastic cylindrical arterial model. Additionally, some authors claim that CorT is a common finding seen with aging and hypertension due to elongation and dilatation of the arteries associated with left ventricular hypertrophy $[15,16]$.

CorT is a common coronary angiographic finding. There are several possible mechanisms accuse of development CorT. Some authors claimed that degeneration of elastin layer of the vessel may be the cause of coronary tortuosity [17]. CorT might induce subclinical atherosclerosis in the absence of significant obstructive lesions [18]. Severe tortuosity in coronary arteries simplifies atherosclerosis [19]. Hereby, atherosclerosis is more common in patients with coronary artery tortuosity as greater curvature has more areas of low shear wall stress.

Impaired arterial endothelial function and increased carotid intima-media thickness (IMT) were associated with vitamin B12 deficiency. Su et al. [20,21] have found lower vitamin B12, higher Hcy, lower brachial artery resistance in Chinese vegetarians. Kwok et al. [22]reported that strong association between vascular dysfunction and higher plasma Hcy, lower vitamin B12 in Chinese non-smoking vegetarians. Carotid IMT, and brachial flow mediated dilatation were significantly worse in patients with vitamin B12 deficiency than that patients with normal vitamin B12 level $[23,24]$. Increased cardiovascular risk factors among German vegans and found that vitamin B12 was the only predictor of Hcy concentration [25,26]. Karabudak et al. [27] founden that similar correlation between vitamin B12 and serum Hcy concentration among Turkish women. Vitamin B12 level was the most significant predictor of Hcy among vegans and vegetarians [28].

Studies haves illustrated several mechanism for the role of hyperhomocysteinemia in atherogenesis, including auto-oxidation of Hcy, which leads to synthesis of compounds related to the initiation of atherogenic process, such as superoxide, hydrogen peroxide, superoxide anion. These compounds have been implicated in atherogenesis through oxidation of low-density lipoprotein, supression of nitric oxide synthesis, arterial stifness, endothelial inflamation and foam cell formation $[29,30]$. Chronic hyperhomocysteinemia reduced activity of superoxide dismutase, which is important in the dismutation of superoxide radicals [30]. Mahalle et al. [31] reported a negative association between vitamin B12 and a positive association between Hcy and triglycerids, very-low-density lipoprotein, and C-reactive protein.

In this light of knowledge, we aim to evaluate relation between CorT and vitamin B12. It's well known that there is a strong association between vitamin B12 deficiency and increased oxidative stress [29-31]. And also, CorT is associated with increased oxidative stress process such as aging, HT, DM, and subclinic atherosclerosis. The present study was the first to evaluate 
relationship between CorT and vitamin B12. In our study there was a significant relation between vitamin B12 deficiency and CorT. Further prospective and randomise studies with a larger number of patients are needed on this topic.

\section{Limitations of the study}

Our study has some limitations. First, retrospective study design. Second, small sample size of the present study. Third, the measure of vitamin B12 level was at a single point time. Fourth, the lack of homocysteine levels.

\section{CONCLUSIONS}

To the best or our knowledge, this study is the first to evaluate the relation between CorT and vitamin B12. In our study there was a strong relation between CorT and vitamin B12. Further prospective and randomise studies with a larger number of patients are required due to the relatively small number of patients in the present study.

\section{Conflict of interest: None}

\section{References}

1. Ng KC, Yong QW, Chan SP, Cheng A. Homocysteine, folate and vitamin B12 as risk factors for acute myocardial infarction in a southeast Asian population. Ann Acad Med Singapore 2002; 31; 636-40.

2. Wilcken D.E, Wilcken B. The pathogenesis of coronary artery disease. A possible role for methionine metabolism. J Clin Invest 1976; 57: 1079-82. doi: 10.1172/JCI108350.

3. Yajnik CS, Deshpande SS, Lubree HG, Naik SS, Bhat DS, Uradey BS, Deshpande JA, Rege SS, Refsum H, Yudkin JS. Vitamin B12 deficiency and hyperhomocysteinemia in rural and urban Indians. J Assoc Physicians India 2006; 54: 775-82.

4. Whincup PH, Refsum H, Perry IJ, Morris R, Walker M, Lennon L, Thomson A, Ueland PM, Ebrahim SB. Serum total homocysteine and coronary heart disease: prospective study in middle aged men. Heart 1999; 82: 448-54.

5. Boushey CJ, Beresford SAA, Omenn GS, Motulsky AG. A quantitative assessment of plasma homocysteine as a risk factor for vascular disease. JAMA1995; 274: 1049-57.

6. Turgut O, Yilmaz A, Yalta K, Yilmaz BM, Ozyol A, Kendirlioglu O, Karadas F, Tandogan I. Tortuosity of coronary arteries: an indicator for impaired left ventricular relaxation? Int J Cardiovasc Imaging. 2007; 23: $671-7$

7. Han HC. Twisted blood vessels: symptoms, etiology and biomechanical mechanisms, J. Vasc. Res. 2012; 49: $185-97$.

8. Li Y, Shen C, Ji Y, Feng Y, Ma G, Liu N. Clinical implication of coronary tortuosity in patients with coronary artery disease. PLoS One. 2011; 6: 24232. doi: 10.1371/journal.pone.0024232.

9. Gaibazzi N, Rigo F, Reverberi C. Severe coronary tortuosity or myocardial bridging in patients with chest pain, normal coronary arteries, and reversible myocardial perfusion defects. Am J Cardiol. 2011; 108: 9738. doi: 10.1016/j.amjcard.2011.05.030.

10. Li Y, Liu NF, Gu ZZ, Chen Y, Lu J, Feng Y, Ma GS, Shen CX. Coronary tortuosity is associated with reversible myocardial perfusion defects in patients without coronary artery disease. Chin Med J (Engl). 2012; 125: 3581-3. 
11. Zegers ES, Meursing BT, Zegers EB, Oude Ophuis AJ. Coronary tortuosity: a long and winding road. Neth Heart J. 2007; 15: 191-5.

12. Lang RM, Bierig M, Devereux RB, Flachskampf FA, Foster E, Pellikka PA, Picard MH, Roman MJ, Seward J, Shanewise J, Solomon S, Spencer KT, St John Sutton M, Stewart W; American Society of Echocardiography's Nomenclature and Standards Committee; Task Force on Chamber Quantification; American College of Cardiology Echocardiography Committee; American Heart Association; European Association of Echocardiography, European Society of Cardiology. Recommendations for chamber quantification. Eur J Echocardiogr 2006; 7: 79-108.

13. Appleton CP, Jensen JL, Hatle L, Oh JK. Doppler evaluation of left and right ventricular diastolic function: a technical guide for obtaining optimal flow velocity recordings. J Am Soc Echocardiogr 1997; 10: $271-92$.

14. Li Y, Shen C, Ji Y, Feng Y, Ma G, Liu N. Clinical implication of coronary tortuosity in patients with coronary artery disease. PLoS One. 2011; 6: 24232. doi: 10.1371/journal.pone.0024232.

15. Del Corso L, Moruzzo D, Conte B, Agelli M, Romanelli AM, Pastine F, Protti M, Pentimone F, Baggiani G. Tortuosity, kinking, and coiling of the carotid artery: expression of atherosclerosis or aging? Angiology 1998; 49: 361-71.

16. Hutchins GM, Bulkley BH, Miner MM, Boitnott JK. Correlation of age and heart weight with tortuosity and caliber of normal human coronary arteries, Am. Heart J. 1977; 94: 196-202.

17. Jakob M, Spasojevic D, Krogmann ON, Wiher H, Hug R, Hess OM. Tortuosity of coronary arteries in chronic pressure and volume overload. Cathet Cardiovasc Diagn. 1996; 38: 25-31.

18. El Tahlawi M, Sakrana A, Elmurr A, Gouda M, Tharwat M. The relation between coronary tortuosity and calcium score in patients with chronic stable angina and normal coronaries by CT angiography. Atherosclerosis. 2016; 246: 334-37. doi: 10.1016/j.atherosclerosis.2016.01.029.

19. Cunningham KS, Gotlieb AI. The role of shear stress in the pathogenesis of atherosclerosis. Lab Invest. 2005; 85: 9-23.

20. Su TC, Jeng JS, Wang JD, Torng PL, Chang SJ, Chen CF, Liau CS. Homocysteine, circulating vascular cell adhesion molecule and carotid atherosclerosis in postmenopausal vegetarian women and omnivores. Atherosclerosis 2006; 184: 356-62. doi:10.1016/j.atherosclerosis.2005.04.022.

21. Su TC, Torng PL, Jeng JS, Chen MF, Liau CS. Arterial function of carotid and brachial arteries in postmenopausal vegetarians. Vasc. Health Risk Manag 2011; 7: 517-23. doi: 10.2147/VHRM.S18881.

22. Kwok T, Chook P, Tam L, Qiao M, Woo JL, Celermajer DS, Woo KS. Vascular dysfunction in Chinese vegetarians: An apparent paradox? J. Am. Coll. Cardiol. 2005; 46: 1957-8. doi:10.1016/j.jacc.2005.07.054.

23. Woo KS, Chook P, Yip TWC, Kwong SK, Hu YJ, Huang XS, Wang GG, Wu MJ, Liu YM, Lam CWK, DS Celermajer. Folic acid and vitamin B-12 supplementation improves arterial function and structure in subjects with subnormal intake. Heart Lung Circ. 2008; 17: 201-2.

24. Woo KS., Chook P, Lolin WI., Sanderson JE., Metreweli C, Celermajer DS. Folic acid improves arterial endothelial function in adults with hyperhomocysteinemia. J. Am. Coll. Cardiol. 1999; 34: 2002-6. doi: 10.1016/S0735-1097(99)00469-6.

25. Waldman A, Koschizke JW, Leitzmann C, Hahn A. German vegan study; diet, life-style factors, and cardiovascular risk profile. Ann Nutr Metab. 2005; 49: 366-72. doi:10.1159/000088888.

26. Herrmann W, Schorr H, Purschwitz K, Rassoul F, Richter V. Total homocysteine, vitamin B(12), and total antioxidant status in vegetarians. Clin Chem. 2001; 47: 1094-101. 
27. Karabudak E, Kiziltan G, Cigerim N. A comparison of some of the cardiovascular risk factors in vegetarian and omnivorous Turkish females. J Hum Nutr Diet 2008; 21: 13-22. doi: 10.1111/j.1365277X.2007.00831.x.

28. Bissoli L, Di Francesco V, Ballarin A, Mandragona R, Trespidi R, Brocco G, Caruso B, Bosello O, Zamboni M. Effect of vegetarian diet on homocysteine levels. Ann Nutr Metab 2002; 46: 73-9. doi:10.1159/000057644.

29. Welch G.N, Loscalzo J. Homocysteine and atherothrombosis. N Engl J Med 1998; 338: 1042-50. doi: 10.1056/NEJM199804093381507.

30. Shargorodsky M, Boaz M, Pasternak S, Hanah R, Matas Z, Fux A, Beigel Y, Mashavi M. Serum homocysteine, folate, vitamin $\mathrm{B}_{12}$ levels and arterial stiffness in diabetic patients: which of them is really important in atherogenesis? Diabetes Metab Res Rev 2009; 25: 70-5. doi: 10.1002/dmrr.902.

31. Mahalle N, Kulkarni MV, Garg MK, Naik SS. Vitamin B12 deficiency and hyperhomocysteinemia as correlates of cardiovascular risk factors in Indian subjects with coronary artery disease. J Cardiol 2013; 61: 289-94. doi: 10.1016/j.jjcc.2012.11.009.

(C) 2016 by the authors; licensee Preprints, Basel, Switzerland. This article is an open access article distributed under the terms and conditions of the Creative Commons by Attribution (CC-BY) license (http://creativecommons.org/licenses/by/4.0/). 